\title{
Valor nutricional de silagem de capim-mombaça com aditivos agroindustriais
}

\author{
Nutritional value of grass silage of mombasa associated with \\ additives agroindustrial
}

\author{
Euclides Reuter de Oliveira ${ }^{1}$; Flávio Pinto Monção ${ }^{2 *}$ Lais Valenzuela Moura ${ }^{3}$; \\ Andréa Maria de Araújo Gabriel ${ }^{1}$; Rafael Henrique de Tonissi e Buschinelli de Góes ${ }^{1}$; \\ Beatriz Lempp ${ }^{1}$; Felipe de Almeida Nascimento ${ }^{4}$
}

\begin{abstract}
Resumo
Objetivou-se avaliar a composição química da silagem de capim-mombaça associada com diferentes aditivos em quatro tempos de abertura do silo. O experimento foi conduzido na UFGD. Após a colheita da forragem, a biomassa in natura triturada, foi levada ao laboratório, homogeneizada e enriquecida, na base da massa natural, com os seguintes aditivos: $5 \%$ de farelo de trigo, $5 \%$ de resíduos (grão quebrado e casquinha de soja) de soja, $5 \%$ de ureia da matéria natural e a testemunha (sem aditivo). Os silos foram abertos após (matéria in natura), 15, 30 e 45 dias, para a análise da composição química. Os dados obtidos foram analisados por meio do programa estatístico SISVAR e as médias foram comparadas a $5 \%$ de probabilidade, pelo teste de Skott-Knot. A silagem de capim-mombaça sem aditivo apresentou maior $(\mathrm{P}<0,05)$ teor de matéria seca em relação aos demais tratamentos no tempo 0 e 30 dias de ensilado e não diferiu $(\mathrm{P}>0,05)$ da silagem de capim-mombaça associada com 5\% de ureia nos dias 15 e 45 de ensilagem. A silagem de capim-mombaça com 5\% de ureia apresentou maior teor de proteína bruta no tempo 0 de abertura e diferiu dos demais tratamentos. A silagem de mombaça associada com $5 \%$ de ureia proporcionou maior digestibilidade in vitro da matéria seca aos 15 dias de ensiladas.

Palavras-chave: Conservação de forragens, nutrição animal, panicum maximum, valor nutricional
\end{abstract}

\begin{abstract}
It was aimed to evaluate the chemical composition of grass silage-mombasa associated with different additives in four times of opening the silo. The experiment was conducted in UFGD. After harvesting the forage, biomass in natura crushed, was taken to the lab, homogenized and enriched on the basis of natural mass, with the following additives: $5 \%$ wheat bran, $5 \%$ of waste (broken grain and soy ice cream cone) of soybean, $5 \%$ urea in natural matter and the witness (without additive). The silos were opened after (unprocessed material), 15, 30 and 45 days, for the analysis of chemical composition. The data obtained were analyzed through the statistical programme SISVAR and averages were compared to $5 \%$ of probability, by Skott-Knot. The grass silage- mombasa without additive presented major $(\mathrm{P}<0.05)$ dry matter content compared to other treatments at time 0 and 30 days of silage and did not differ $(\mathrm{P}>0.05)$ of grass silage- mombasa associated with 5 of urea in 15 days and 45 of silage. The grass
\end{abstract}

\footnotetext{
${ }^{1}$ Profs. Drs. da Faculdade de Ciências Agrárias, Universidade Federal da Grande Dourados, UFGD, Dourados, MS. E-mail: euclidesoliveira@ufgd.edu.br; andrea.gabriel@ufgd.edu.br; rafaelgoes@ufgd.edu.br; beatrizlempp@ufgd.edu.br

${ }^{2}$ Discente de Doutorado em Zootecnia, Faculdade de Ciências Agrárias e Veterinária, Universidade Estadual Paulista "Júlio de Mesquita Filho", UNESP, Jaboticabal, SP. E-mail: moncaomoncao@yahoo.com.br

${ }^{3}$ Discente de Mestrado em Zootecnia, UFGD, Dourados, MS. E-mail: valenzuelamoura@bol.com.br

${ }^{4}$ Discente do curso de Zootecnia, UFGD, Dourados, MS. E-mail: phelipe_nascimento@hotmail.com

* Autor para correspondência
} 
silage-mombasa with 5\% urea showed the highest crude protein content at time 0 and differed from other treatments. The silage of mombasa associated with $5 \%$ urea provided greater in vitro digestibility of dry matter to 15 days of silage.

Key words: Animal nutrition, conservation of forage, nutritional value, panicum maximum

\section{Introdução}

O sistema mais econômico para a alimentação de animais herbívoros é, sem dúvida, a utilização direta do pasto. Entretanto, o Brasil é um país tropical e possui, genericamente, duas estações distintas - um período quente, chuvoso e de dias longos, possibilitando intensa produção vegetal e, consequentemente, animal, e um período seco, de temperaturas amenas e dias curtos, onde há escassez de alimentos e, consequentemente, queda na produção dos animais que dependem exclusivamente das forrageiras (LANES et al., 2006). Neste sentido, as plantas têm seu crescimento e qualidade variável conforme a época do ano, alternando ocasiões de maior e menor crescimento e valor nutritivo. Quando se tem um número instável de animais que se alimentam desta forragem, constantemente, observam-se períodos em que há falta desse volumoso e, por outro lado, tempos em que há excesso do mesmo (ZAGO, 2011). Para diminuir esse problema, diversos métodos têm sido pesquisados e utilizados para suprir o déficit alimentar nos rebanhos mantidos em regime de campo, e o mais comum, é a confecção de silagem.

Neste contexto, a conservação de forragens verdes na forma de silagem é uma estratégia para contornar o problema de escassez de pasto no período de estiagem. Para confecção de silagens, o milho tem sido a forrageira que mais se destaca quanto aos aspectos nutricionais e de adequação ao processo fermentativo (ALVES et al., 2012), no entanto, podese utilizar uma grande variedade de gramíneas e leguminosas (RODRIGUES et al., 2001).

As gramíneas de clima tropical, dentre elas o capim-mombaça (Panicum maximum Jack. cv. Mombaça), apresentam elevada produção de biomassa seca. Isso gera um excedente de forragem, que pode ser aproveitado na forma de silagem para utilização na época de escassez (VASCONCELOS et al., 2009).

Todavia, essas gramíneas apresentam baixo teor de massa seca, alto poder-tampão e baixo teor de carboidratos solúveis nos estádios de crescimento em que apresentam bom valor nutritivo, colocando em risco o processo de conservação por meio da ensilagem, devido às possibilidades de surgirem fermentações secundárias (EVANGELISTA et al., 2004).

As características das forrageiras que favorecem uma boa fermentação são o teor de massa seca, a microbiota epifítica e, principalmente, a quantidade de carboidratos solúveis. Alguns capins podem ser aproveitados, desde que sejam ensilados no estádio de desenvolvimento ideal ou se empreguem aditivos adequados (ZANINE et al., 2006).

A utilização de aditivos em silagens de genótipos pertencente ao gênero Panicum pode melhorar a qualidade do processo fermentativo e valor nutricional. Os inoculantes microbianos são muito utilizados em todo o mundo, em virtude da segurança e facilidade de uso, além de não serem corrosivos e não poluírem o ambiente. Existe grande número de estudos sobre o uso de aditivos em silagens, porém, os resultados relacionados às melhorias do processo fermentativo, ao valor nutritivo, ao consumo de matéria seca e ao ganho de peso dos animais ainda são contraditórios (ÁVILA et al., 2009), principalmente quando os aditivos são resíduos de agroindustriais.

Neste contexto, objetivou-se avaliar a composição química da silagem de capim-mombaça (Panicum maximum) associada com diferentes aditivos agroindustriais em diferentes tempos de abertura. 


\section{Material e Métodos}

O experimento foi realizado nas dependências do campo agrostológico e no Laboratório de Nutrição Animal da Faculdade de Ciências Agrárias da Universidade Federal da Grande Dourados UFGD entre os meses de setembro de 2010 a junho de 2011.

Foi utilizada uma parcela de $5 \mathrm{~m}^{2}$ implantada com P. maximum cv. Mombaça, onde após o corte de uniformização (10 cm do solo) a forragem foi colhida aos 70 dias de rebrota (1,5 metros de altura). $\mathrm{O}$ corte das plantas para a ensilagem foi feito com o auxílio de uma ensiladeira regulada para tamanho médio de partículas de $1,5 \mathrm{~cm}$ e altura de corte de $10 \mathrm{~cm}$.

O solo é classificado como latossolo vermelho distroférrico (EMBRAPA, 2006) o qual apresentou as seguintes características químicas (Tabela 1).

Tabela 1. Análise química do solo da região de Dourados-MS.

\begin{tabular}{|c|c|c|c|c|c|c|c|c|c|c|c|}
\hline Profundidade & $\mathrm{pH} \mathrm{H_{2 } \mathrm { O }}$ & P Leitura & $P$ & $\mathrm{Ca}$ & $\mathrm{Mg}$ & $\mathrm{k}$ & $\mathrm{Al}$ & $\mathrm{H}+\mathrm{Al}$ & SB & $\mathrm{T}$ & $\mathrm{V}$ \\
\hline $\mathrm{cm}$ & & & $\mathrm{m} \cdot \mathrm{g} / \mathrm{dm}^{3}$ & --- & 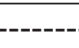 & - & $-\mathrm{Cm}$ & 1 c----- & ------ & - & $\%$ \\
\hline $0-20$ & 6,14 & 0,05 & 4,56 & 6,80 & 2,46 & 0,17 & 0,24 & 1,14 & 9,42 & 12,55 & 75,10 \\
\hline
\end{tabular}

Fonte: Elaboração dos autores.

Realizou-se a adubação de manutenção com 50 $\mathrm{kg}$ de ureia/ha, $211 \mathrm{~kg}$ de $\mathrm{P}_{2} \mathrm{O}_{5} /$ ha e $40 \mathrm{~kg}$ de $\mathrm{K}_{2} \mathrm{O}$ / ha, conforme análise do solo e recomendação de Costa et al., (2003) para o genótipo Mombaça.

Após a colheita da forragem, a biomassa in natura triturada foi levada ao laboratório, homogeneizada e enriquecida na base da massa natural com os seguintes aditivos: $5 \%$ de farelo de trigo, 5\% de resíduos (grão quebrado e casquinha de soja) de soja, 5\% de ureia da matéria natural e a testemunha (sem aditivo). Foram confeccionados 48 silos experimentais a partir de garrafas plásticas com $150 \mathrm{~mm}$ de diâmetro e $252 \mathrm{~mm}$ de altura, adotando-se compactação de $500 \mathrm{~kg} / \mathrm{m}^{3}$ segundo a metodologia recomendada por Ruppel et al., (1995).

O delineamento experimental adotado foi $\mathrm{o}$ inteiramente casualizado, em esquema fatorial com quatro tratamentos (fator $\mathrm{A}$ ), quatro tempos de abertura (fator B) dos silos e três repetições.

$\mathrm{Na}$ parte interna dos silos utilizou-se uma rede de náilon e algodão para absorver o excesso de umidade. Os silos experimentais foram vedados com lona plástica nas duas extremidades, utilizando- se arame liso galvanizado e fita plástica para o fechamento, e armazenados em galpão coberto.

Os tempos de abertura foram 15, 30 e 45 dias de ensilados e também analisada a matéria in natura (testemunha). As amostras dos materiais nos diferentes tempos de abertura dos silos foram pré-secas em estufa de ventilação forçada a 55$65^{\circ} \mathrm{C}$ até estabilizar o peso. Posteriormente, as amostras foram moídas em peneira com crivo de $1 \mathrm{~mm}$ em moinho "Tipo Willey". Após a moagem o material foi acondicionado em frascos de vidro para análises bromatológicas. Avaliaram-se o teor de massa seca (MS), proteína bruta (PB), e matéria mineral (MM) seguindo a metodologia descrita por Silva e Queiroz (2002). A fibra em detergente neutro (FDN) e em detergente ácido (FDA) foi avaliada conforme recomendações de Van Soest, Robertson e Lewis (1991). Para determinação do potencial hidrogêniônico $(\mathrm{pH})$, foi coletado uma amostra de 50 gramas de cada silo e adicionado $50 \mathrm{ml}$ de água destilada e após 30 minutos feito a mensuração utilizando o p-agâmetro conforme Silva e Queiroz (2002).

O ensaio de digestibilidade "in vitro" da 
matéria seca (DIVMS), foi conduzido segundo a metodologia descrita por Tilley e Terry (1963) e para a determinação da Lignina utilizou-se o método permanganato segundo a metodologia de Silva e Queiroz (2002). A composição bromatológica dos aditivos utilizados está na tabela 2 .

Tabela 2. Composição Bromatológica do resíduo de soja e farelo de trigo, utilizados como aditivos.

\begin{tabular}{lcccc}
\hline \multirow{2}{*}{ ADITIVOS } & \multicolumn{4}{c}{ COMPOSIÇÃO BROMATOLÓGICA } \\
\cline { 2 - 5 } & MS (\%) & PB (\% da MS) & FDN (\% da MS) & FDA (\% da MS) \\
\hline Resíduo de Soja & 86,60 & 32,50 & 72,60 & 14,30 \\
Farelo de trigo & 88,00 & 16,40 & 51,34 & 7,24 \\
\hline
\end{tabular}

Fonte: Elaboração dos autores.

Os dados obtidos foram analisados por meio do programa estatístico SISVAR 5.2 e as médias foram comparadas a $5 \%$ de probabilidade, pelo teste de Skott-Knott.

\section{Resultados e Discussão}

Em relação a adição de aditivos agroindustriais em silagens de capim-mombaça, é possível observar que houve uma variação significativa dos valores de $\mathrm{pH}$ entre os tempos de abertura dos silos $(\mathrm{P}<0,05)$ tanto para as silagens com aditivos quanto para a testemunha (sem aditivos) (Tabela 3 ). Conforme pode-se observar na tabela $3, \mathrm{o} \mathrm{pH}$ da silagem sem aditivos reduziu lentamente de 6,20 para 4,88, com 15 dias de fermentação; dos 15 para 30 dias, observou-se um pequeno aumento no $\mathrm{pH}$, voltando a cair novamente até os 45 dias, resultando em uma silagem com um $\mathrm{pH}$ de 4,82 .

Tabela 3. Determinação dos valores de $\mathrm{pH}$ das silagens de capim-mombaça em função dos tempos de abertura e diferentes aditivos agroindustriais.

\begin{tabular}{lcccc}
\hline \multirow{2}{*}{ TRATAMENTO } & \multicolumn{4}{c}{ ÉPOCA DE ABERTURA } \\
\cline { 2 - 5 } & 0 & 15 & 30 & 45 \\
\hline SM & $6,20 \mathrm{Ba}$ & $4,88 \mathrm{Cb}$ & $5,15 \mathrm{Bc}$ & $4,82 \mathrm{Dc}$ \\
$\mathrm{SM}+\mathrm{FT}$ & $6,42 \mathrm{Aa}$ & $4,71 \mathrm{Cb}$ & $5,16 \mathrm{Bb}$ & $4,99 \mathrm{Cc}$ \\
$\mathrm{SM}+\mathrm{RS}$ & $6,27 \mathrm{Ba}$ & $5,11 \mathrm{Bc}$ & $5,16 \mathrm{Bb}$ & $5,79 \mathrm{Bb}$ \\
$\mathrm{SM}+\mathrm{U}$ & $6,12 \mathrm{Bb}$ & $8,83 \mathrm{Aa}$ & $8,68 \mathrm{Aa}$ & $8,78 \mathrm{Aa}$ \\
\hline \multicolumn{4}{c}{$\mathrm{CV}(\%)=1,69$} \\
\hline
\end{tabular}

Médias seguidas de mesma letra maiúscula na coluna e minúscula na linha, não diferem entre si pelo teste de Scott-Knott a 5\% de probabilidade. CV: Coeficiente de Variação SM- Silagem de Mombaça; SM+FT- Silagem de Mombaça + 5\% de farelo de trigo; SM+RS- Silagem de Mombaça + 5\% de Resíduo de Soja; SM+U- Silagem de Mombaça + 5\% de ureia

Fonte: Elaboração dos autores.

Com relação às silagens com aditivos, houve diferença significativa nos valores de $\mathrm{pH}$ entre os tempos de abertura dos silos sendo verificado redução no $\mathrm{pH}$ com o incremento na época de abertura, exceto para a silagem de capim-mombaça com ureia que aumentou o $\mathrm{pH}$. Houve aumento de 6,12 para 8,83, com quinze dias de fermentação, e a partir daí, observou-se uma estabilização do $\mathrm{pH}$ até 45 dias de fermentação, resultando em uma silagem com $\mathrm{pH}$ de 8,78 aos 45 dias. 
Comparando os valores médios de $\mathrm{pH}$ da silagem sem aditivo $(5,26)$ e com aditivos (valor médio dos tratamentos de 6,33) (Tabela 3), constata-se a eficiência dos aditivos na redução do $\mathrm{pH}$, com exceção da ureia que é um aditivo alcalinizante. Esses resultados estão coerentes com os obtidos por Ávila et al. (2003) que observaram eficiência dos aditivos na melhoria da qualidade de fermentação que pode ser explicada pelo fornecimento de carboidratos solúveis e consequentemente, aumento do teor de MS ou redução do poder tampão da forragem, o que influenciou na redução do $\mathrm{pH}$ da silagem.

No presente experimento, a utilização dos aditivos contribuíram para aumentar o teor de MS das silagens (Tabela 4) devido ao alto teor de MS dos mesmos (Tabela 2), reduzindo, assim, a atividade de bactérias do gênero Clostridium que são sensíveis à pressão. No entanto, Woolford (1984), sugeriu que o pH final não pode ser tomado isoladamente como um bom critério para avaliação das fermentações, pois a inibição de fermentações secundárias depende mais da velocidade de abaixamento do mesmo, da concentração iônica e da umidade do meio do que do $\mathrm{pH}$ final do produto. Segundo o mesmo autor, o $\mathrm{pH}$ ideal resultante de uma boa fermentação deve ser menor que 4,2; porém, mesmo as silagens sem aditivos, com $\mathrm{pH}$ de 4,82 mostraram bom aspecto de conservação.
$\mathrm{Na}$ Tabela 4 pode ser observado o teor de MS nos diferentes tempos de fermentação. Nota-se que houve diferença significativa $(\mathrm{P}<0,05)$ para o teor de matéria seca da silagem de capim-mombaça entre os tratamentos e não houve interação $(\mathrm{P}>0,05)$ entre os tratamentos e tempos de abertura. Isso ocorreu provavelmente devido à mudança na relação entre a parede celular e o conteúdo celular. Quanto menor a idade da planta, menor é a quantidade de componentes (celulose, hemicelulose, lignina) da parede celular (constituinte da matéria seca) e maior é a concentração do conteúdo celular (carboidratos solúveis, proteínas). No entanto, com o avanço da idade, há um aumento na concentração dos constituintes da parede celular promovendo a diminuição do conteúdo celular e aumento da matéria seca (VAN SOEST; ROBERTSON; LEWIS, 1991).

A composição bromatológica da silagem de capim-mombaça (sem aditivo) apresentou valores semelhantes aos encontrados na literatura, com poucas variações, mas em geral coerentes com os relatados para gramíneas da espécie Panicum maximum com 60 a 70 dias de idade conforme trabalhos de Ávila et al., (2009); Vieira et al., (2010); Pariz et al., (2011). Ao final do período fermentativo, os valores de MS para silagem de capim-mombaça, variaram entre 44,50 e $60,62 \%$, do menor para o maior tempo de abertura.

Tabela 4. Teores de matéria seca das silagens de campim-mombaça com diferentes aditivos e segundo o tempo de abertura.

\begin{tabular}{lcccc}
\hline \multirow{2}{*}{ TRATAMENTO } & \multicolumn{4}{c}{ ÉPOCA DE ABERTURA } \\
\cline { 2 - 5 } & 0 & 15 & 30 & 45 \\
\hline $\mathrm{SM}$ & $53,62 \mathrm{Ac}$ & $58,01 \mathrm{Ab}$ & $60,97 \mathrm{Aa}$ & $60,62 \mathrm{Aa}$ \\
$\mathrm{SM}+\mathrm{FT}$ & $49,20 \mathrm{Bd}$ & $51,36 \mathrm{Cc}$ & $54,89 \mathrm{Cb}$ & $58,41 \mathrm{Ba}$ \\
$\mathrm{SM}+\mathrm{RS}$ & $44,50 \mathrm{Cc}$ & $55,84 \mathrm{Bb}$ & $53,71 \mathrm{Ca}$ & $56,80 \mathrm{Ba}$ \\
$\mathrm{SM}+\mathrm{U}$ & $47,69 \mathrm{Bb}$ & $58,53 \mathrm{Aa}$ & $58,82 \mathrm{Ba}$ & $60,04 \mathrm{Aa}$ \\
\hline \multicolumn{5}{c}{} \\
\hline
\end{tabular}

Médias seguidas de mesma letra, maiúscula na coluna e minúscula na linha, não diferem entre si pelo teste de Scott-Knott a 5\% de probabilidade. CV: Coeficiente de Variação SM- Silagem de Mombaça; SM+FT- Silagem de Mombaça + 5\% de farelo de trigo; SM+RS- Silagem de Mombaça + 5\% de Resíduo de Soja; SM+U- Silagem de Mombaça + 5\% de ureia.

Fonte: Elaboração dos autores. 
A silagem de capim-mombaça sem aditivo apresentou maior teor de matéria seca em quase todas as idades analisadas. Devido os aditivos (farelo de trigo e resíduo de soja) apresentarem carboidratos de alta fermentação, isso favoreceu a degradação da parede celular da silagem e consequentemente a sua redução no teor da matéria seca, em relação a silagem testemunha. Neste contexto, Ávila et al., (2009) sugerem que a avaliação dos teores de carboidratos solúveis, matéria seca e poder tampão servem para avaliar a viabilidade de ensilagem de uma forrageira.

A silagem de capim-mombaça in natura (sem aditivo) apresentou teor de matéria seca de 53,62\%. Esses resultados são superiores aos obtidos por Santana et al., (2010) que avaliaram o teor de massa seca de silagem de capim-mombaça em diferentes dosagens de corretivos e encontraram teores de massa seca de $36,71 \%$ para o grupo controle e 50 dias de idade. Neste contexto, nota-se que idade de corte foi um fator importante no acúmulo de massa seca, pois segundo Blaser (1982) uma vez que ocorre intensificação no processo de alongamento do colmo e diminuição progressiva na proporção de folhas, há consequente redução do conteúdo celular e do valor nutritivo da planta.

Ávila et al., (2009) avaliaram a composição química de silagem de capim-mombaça com tempo de abertura aos 90 dias, obtiveram teores de matéria seca de $28,59 \%$, valor este inferior aos obtidos neste experimento. No entanto, esses dados devem ser examinados com cautela, uma vez que outros fatores podem afetar o processo fermentativo, como, por exemplo, estrutura física da forragem, compactação, capacidade tamponante e população autóctone de bactérias lácticas (VASCONCELOS et al., 2009).

A compactação, inclusão de aditivo absorvente e emurchecimento de capim-tanzânia, são fatores essenciais no incremento da densidade de compactação da massa no interior do silo com respostas positivas sobre o processo fermentativo e a redução do pH (TAVARES et al., 2009). Estes mesmos autores encontraram teores de MS para a silagem de capim-tanzânia, ensilada aos 65 dias de crescimento, de 29, 69 e 21,63\% para silagem contendo $5 \%$ de polpa cítrica na matéria natural.

Não houve diferença significativa $(\mathrm{P}>0,05)$ para os teores de proteína bruta dentro dos tratamentos analisados no tempo de abertura 15; 30 e 45 dias. Não houve interação $(\mathrm{P}>0,05)$ entre os tratamentos e os tempos de abertura para os teores de proteína bruta. Observa-se que a silagem associada com $5 \%$ de ureia apresentou maior teor médio de proteína bruta, no entanto, a partir dos 15 dias de fermentação não diferiu $(\mathrm{P}>0,05)$ dos demais tratamentos (Tabela 5).

Tabela 5. Teores de proteína bruta das silagens de campim-mombaça tratadas com diferentes aditivos agroindustriais e segundo o tempo de abertura.

\begin{tabular}{lcccc}
\hline \multirow{2}{*}{ TRATAMENTO } & \multicolumn{4}{c}{ ÉPOCA DE ABERTURA } \\
\cline { 2 - 5 } & 0 & 15 & 30 & 45 \\
\hline $\mathrm{SM}$ & $6,27 \mathrm{Ba}$ & $6,80 \mathrm{Aa}$ & $5,86 \mathrm{Aa}$ & $5,45 \mathrm{Aa}$ \\
$\mathrm{SM}+\mathrm{FT}$ & $7,98 \mathrm{Ba}$ & $10,10 \mathrm{Aa}$ & $7,44 \mathrm{Aa}$ & $8,04 \mathrm{Aa}$ \\
$\mathrm{SM}+\mathrm{RS}$ & $10,83 \mathrm{Ba}$ & $9,23 \mathrm{Aa}$ & $8,71 \mathrm{Aa}$ & $8,21 \mathrm{Aa}$ \\
$\mathrm{SM}+\mathrm{U}$ & $33,40 \mathrm{Aa}$ & $9,07 \mathrm{Ab}$ & $10,00 \mathrm{Ab}$ & $10,24 \mathrm{Ab}$ \\
\hline \multicolumn{5}{c}{} \\
\hline
\end{tabular}

Médias seguidas de mesma letra, maiúscula na coluna e minúscula na linha, não diferem entre si pelo teste de Scott-Knott a 5\% de probabilidade. CV: Coeficiente de Variação. SM- Silagem de Mombaça; SM+FT- Silagem de Mombaça + 5\% de farelo de trigo; SM+RS- Silagem de Mombaça + 5\% de Resíduo de Soja; SM+U- Silagem de Mombaça + 5\% de ureia.

Fonte: Elaboração dos autores. 
Devido à ureia desassociar rapidamente na presença de umidade, é justificável o alto pico de amônia da silagem de capim-mombaça associada com ureia antes de ensilar, uma vez que o equivalente protéico da ureia varia de 245 a $280 \%$. No entanto, aos 45 dias de fermentação, não houve diferença $(\mathrm{P}>0,05)$ no teor de proteína bruta entre os tratamentos, possivelmente devido ao alto coeficiente de variação. Desta forma, a adição de ureia na silagem de capim-mombaça ou forragem triturada seria interessante quando utilizada em momentos antes do fornecimento aos animais, pois a eficiência da ureia seria melhor.

Mesmo não havendo diferença $(\mathrm{P}>0,05)$ significativa para os teores de $\mathrm{PB}$ aos 45 dias é recomendável a utilização de uma fonte proteica, pois somente a silagem de capim-mombaça com $5,45 \%$ de $\mathrm{PB}$, está abaixo do preconizado para que ocorra um desenvolvimento reprodutivo e funcional da microbiota ruminal (VAN SOEST, 1994).

A avaliação do teor de proteína é importante devido sua essencialidade direta para o organismo animal, para fins de mantença e produção de carne, leite e lã, além da via de atividade da microbiota presente no rúmen (LANA, 2005). Embora o mínimo de $7 \%$ de proteína bruta na matéria seca preconizado por Van Soest (1994) seja necessário para garantir a fermentação dos carboidratos estruturais no rúmen, um valor superior é interessante para o atendimento das exigências protéicas do organismo animal que varia conforme a raça, idade, sexo, categoria e aptidão.

Zanine et al., (2006) avaliaram o efeito do farelo de trigo sobre as perdas, recuperação da matéria seca e composição bromatológica de silagem de capim-mombaça ensilado aos 50 dias de rebrota, encontraram teor médio de $9,4 \%$ de PB. Esses resultados são superiores aos obtidos neste trabalho que foi de 6,09\%. Essa diferença nos teores se deu provavelmente, devido à intensificação da adubação nitrogenada utilizada que foi de $100 \mathrm{~kg}$ de ureia/ha enquanto neste experimento foram utilizados $50 \mathrm{~kg}$ de ureia /ha. Conforme os autores, a adubação nitrogenada pode alterar o teor de proteína das plantas.

O teor de FDN do tratamento silagem de mombaça associada com 5\% farelo de trigo, reduziu significativamente $(\mathrm{P}<0,05)$ aos 15 e 30 dias de tempo de abertura como pode ser observado na Tabela 6 . Provavelmente, durante o processo de ensilagem, ocorreram perdas decorrentes da produção de água, gás e calor, durante a fermentação e/ou por efluentes, Van Soest (1994), em que favoreceu a redução nos componentes (celulose, hemicelulse, proteína danificada pelo calor e lignina) da FDN (Tabela 4).

Nota-se que os tratamentos apresentaram altos teores de FDN o que não é desejável em uma forragem, uma vez que dependendo das proporções dos constituintes da parede celular principalmente lignina, há redução do consumo pelo animal comprometendo o desempenho (WILSON, 1994).

Pode ser observado na Tabela 6, que em média todos os tratamentos apresentaram teores médios de FDN acima de 70\%, enquanto o valor preconizado ou ideal para ruminantes é de até $55 \%$ da matéria seca (VAN SOEST, 1965). 
Tabela 6. Teores de fibra em detergente neutro das silagens de campim-mombaça com diferentes aditivos agroindustriais e segundo o tempo de abertura.

\begin{tabular}{lcccc}
\hline \multirow{2}{*}{ TRATAMENTO } & \multicolumn{4}{c}{ ÉPOCA DE ABERTURA } \\
\cline { 2 - 5 } & 0 & 15 & 30 & 45 \\
\hline SM & $82,56 \mathrm{Aa}$ & $83,12 \mathrm{Aa}$ & $79,74 \mathrm{Aa}$ & $78,69 \mathrm{Aa}$ \\
$\mathrm{SM}+\mathrm{FT}$ & $80,38 \mathrm{Aa}$ & $88,77 \mathrm{Aa}$ & $68,46 \mathrm{Bb}$ & $75,63 \mathrm{Ab}$ \\
$\mathrm{SM}+\mathrm{RS}$ & $80,72 \mathrm{Aa}$ & $70,50 \mathrm{Ba}$ & $75,50 \mathrm{Aa}$ & $75,96 \mathrm{Aa}$ \\
$\mathrm{SM}+\mathrm{U}$ & $73,97 \mathrm{Aa}$ & $79,69 \mathrm{Aa}$ & $80,91 \mathrm{Aa}$ & $81,96 \mathrm{Aa}$ \\
\hline \multicolumn{5}{c}{$\mathrm{CV}(\%)=6,85$} \\
\hline
\end{tabular}

Médias seguidas de mesma letra maiúscula na coluna e minúscula na linha, não diferem entre si pelo teste de Scott-Knott a 5\% de probabilidade. CV: Coeficiente de Variação. SM- Silagem de Mombaça; SM+FT- Silagem de Mombaça + 5\% de farelo de trigo; SM+RS- Silagem de Mombaça + 5\% de Resíduo de Soja; SM+U- Silagem de Mombaça + 5\% de ureia.

Fonte: Elaboração dos autores.

Os constituintes da parede celular das forragens relacionam-se com quatro características dos alimentos, importantes na nutrição animal; está relacionada com a degradabilidade, digestibilidade e com os valores energéticos; com a fermentação ruminal e pode estar envolvida no controle da ingestão de alimento (SILVA et al., 2000).

Pariz et al. (2011) avaliaram a composição bromatológica dos capins tanzânia e mombaça irrigados e adubados com nitrogênio após o consórcio com milho, encontraram teor de FDN, com dosagens de $50 \mathrm{~kg}$ de ureia/ha, de 65,5\%, valores estes inferiores aos obtidos no presente experimento.

Conforme os resultados obtidos para os teores de FDN, sugere-se que o capim-mombaça deve ser cortado em idade inferior aos 70 dias ou com alturas entre 90 a $120 \mathrm{~cm}$ para que tenha um teor de massa seca (28 a 35\%) e FDN (55 a $65 \%$ ) adequado para que ocorra adequada fermentação (VASCONCELOS et al., 2009). Desta forma, há um equilíbrio entre o teor de FDN, de PB e MS.

O teor de fibra em detergente ácido (FDA) das silagens não diferiu $(\mathrm{P}>0,05)$ entre si e em função dos tempos de abertura estudado e não houve interação $(P>0,05)$ entre os tratamentos e o tempo de abertura (Tabela 7). Esse comportamento das silagens com aditivo e sem aditivo quanto ao teor de FDA não está de acordo com os observados na literatura que há relatos de redução no teor de FDA de silagem com aditivos, como mencionado por Jackson (1977), pois, a celulose expandese quando tratada com produtos alcalinos, como a ureia, reduz as ligações intermoleculares das pontes de hidrogênio, as quais ligam moléculas de celulose. Segundo Van Soest (1987) durante o tratamento alcalino, parte da lignina e da sílica pode ser dissolvida. 
Tabela 7. Teores de fibra em detergente ácido das silagens de campim-mombaça com diferentes aditivos agroindustriais e segundo o tempo de abertura.

\begin{tabular}{lcccc}
\hline \multirow{2}{*}{ TRATAMENTO } & \multicolumn{4}{c}{ ÉPOCA DE ABERTURA } \\
\cline { 2 - 5 } & 0 & 15 & 30 & 45 \\
\hline SM & 46,6 & 51,45 & 48,88 & 48,09 \\
SM + FT & 42,57 & 51,1 & 40,84 & 45,33 \\
SM + RS & 44,98 & 42,02 & 46,23 & 47,16 \\
SM + U & 41,82 & 49,88 & 50,69 & 56,21 \\
\hline \multicolumn{4}{r}{} \\
\hline
\end{tabular}

Médias seguidas de mesma letra maiúscula na coluna e minúscula na linha, não diferem entre si pelo teste de Scott-Knott a $5 \%$ de probabilidade. CV: Coeficiente de Variação. SM- Silagem de Mombaça; SM+FT- Silagem de Mombaça $+5 \%$ de farelo de trigo; SM+RS- Silagem de Mombaça + 5\% de Resíduo de Soja; SM+U- Silagem de Mombaça + 5\% de ureia.

Fonte: Elaboração dos autores.

O teor de FDA da silagem controle foi superior ao obtido por Balieiro Neto et al., (2007) que avaliaram óxido de cálcio como aditivo na ensilagem de cana-de-açúcar e encontraram teor de FDA da silagem testemunha de 43,96\% no tempo 0 de abertura e aos 84 dias de fermentação encontraram teor de $47,92 \%$. Segundo os autores, o aumento nos teores de FDA ocorreu principalmente devido ao consumo de carboidratos solúveis por microrganismos durante a ensilagem, o que não ocorreu no presente experimento.

Houve diferença significativa $(\mathrm{P}<0,05)$ para os teores de hemicelulose da silagem de capim-mombaça entre os tratamentos e em cada tempo de abertura e não houve interação $(\mathrm{P}>0,05)$ entre os tratamentos em função dos tempos de abertura (Tabela 8).

Tabela 8. Teores de hemicelulose das silagens de campim-mombaça tratadas com diferentes aditivos e segundo o tempo de abertura.

\begin{tabular}{lcccc}
\hline \multirow{2}{*}{ TRATAMENTO } & \multicolumn{4}{c}{ ÉPOCA DE ABERTURA } \\
\cline { 2 - 5 } & 0 & 15 & 30 & 45 \\
\hline $\mathrm{SM}$ & $35,96 \mathrm{Aa}$ & $31,66 \mathrm{Bb}$ & $30,85 \mathrm{Ab}$ & $30,59 \mathrm{Ab}$ \\
$\mathrm{SM}+\mathrm{FT}$ & $37,81 \mathrm{Aa}$ & $37,66 \mathrm{Aa}$ & $27,62 \mathrm{Ab}$ & $30,30 \mathrm{Ab}$ \\
$\mathrm{SM}+\mathrm{RS}$ & $35,74 \mathrm{Aa}$ & $28,48 \mathrm{Bb}$ & $29,26 \mathrm{Ab}$ & $28,80 \mathrm{Ab}$ \\
$\mathrm{SM}+\mathrm{U}$ & $32,15 \mathrm{Ba}$ & $29,80 \mathrm{Ba}$ & $30,21 \mathrm{Aa}$ & $25,75 \mathrm{Bb}$ \\
\hline \multicolumn{5}{c}{} \\
\hline
\end{tabular}

Médias seguidas de mesma letra maiúscula na coluna e minúscula na linha, não diferem entre si pelo teste de Scott-Knott a 5\% de probabilidade. CV: Coeficiente de Variação. SM- Silagem de Mombaça; SM+FT- Silagem de Mombaça $+5 \%$ de farelo de trigo; SM+RS- Silagem de Mombaça $+5 \%$ de Resíduo de Soja; SM+U- Silagem de Mombaça + 5\% de ureia.

Fonte: Elaboração dos autores.

A diferença entre os teores de hemicelulose para as silagens sem aditivo e com aditivo (exceto para o aditivo ureia) reduziu com os tempos de ensilagem, algumas com 15 dias de fermentação como ocorreu com a silagem de capim-momboça e a silagem de capim-mombaça com resíduo de soja e outra com
30 dias de fermentação como ocorreu com a silagem de capim-mombaça com farelo de trigo. Em relação à silagem com aditivos, o aditivo provavelmente pode ter causado rompimento entre as ligações moleculares do tipo éster entre o ácido urônico da hemicelulose e da celulose, citado por Van Soest 
(1987), por isso tenha ocorrido redução do teor de hemicelulose entre as observações nos diferentes tempos de ensilagem. No entanto, Muck e Kung Junior (1997), relataram que a redução dos teores de hemicelulose das silagens deve-se à presença de hemicelulases na planta ensilada, mas, a efetividade destas enzimas varia significativamente conforme a fonte e os substratos relacionados. Porém, Muck (1996) enfatizou a necessidade de manutenção das silagens sob baixos valores de $\mathrm{pH}$ para que a hemicelulose possa ser quebrada pelas enzimas, sendo este efeito geralmente pequeno.

Os teores de lignina não diferiram $(\mathrm{P}>0,05)$ entre tratamentos e dentro dos tempos de abertura. Segundo Klopfenstein (1980), o teor de lignina normalmente não é alterado, mas, de acordo com Van Soest (1987), a ação do aditivo pode provocar aumento da solubilidade da lignina e da sílica.

Não houve diferença significativa entre os tratamentos no tempo de abertura 0; 30 e 45 para a digestibilidade in vitro da matéria seca (DIVMS) (Tabela 9).

Tabela 9. Digestibilidade in vitro da matéria seca da silagem de mombaça associadas com diferentes aditivos agroindustriais em diferentes tempos de abertura.

\begin{tabular}{lcccc}
\hline \multirow{2}{*}{ TRATAMENTO } & \multicolumn{4}{c}{ ÉPOCA DE ABERTURA } \\
\cline { 2 - 5 } & 0 & 15 & 30 & 45 \\
\hline $\mathrm{SM}$ & $55,45 \mathrm{Aa}$ & $56,20 \mathrm{Ba}$ & $53,13 \mathrm{Aa}$ & $46,01 \mathrm{Ab}$ \\
$\mathrm{SM}+\mathrm{FT}$ & $55,58 \mathrm{Aa}$ & $53,21 \mathrm{Ba}$ & $52,87 \mathrm{Aa}$ & $52,68 \mathrm{Aa}$ \\
$\mathrm{SM}+\mathrm{RS}$ & $56,59 \mathrm{Aa}$ & $49,32 \mathrm{Ba}$ & $53,42 \mathrm{Aa}$ & $50,43 \mathrm{Aa}$ \\
$\mathrm{SM}+\mathrm{U}$ & $60,12 \mathrm{Aa}$ & $65,14 \mathrm{Aa}$ & $49,12 \mathrm{Ab}$ & $51,28 \mathrm{Ab}$ \\
\hline \multicolumn{5}{c}{$\mathrm{CV}(\%)=6,69$} \\
\hline
\end{tabular}

Médias seguidas de mesma letra maiúscula na coluna e minúscula na linha, não diferem entre si pelo teste de Scott-Knott a 5\% de probabilidade. CV: Coeficiente de Variação. SM- Silagem de Mombaça; SM+FT- Silagem de Mombaça + 5\% de farelo de trigo; SM+RS- Silagem de Mombaça $+5 \%$ de Resíduo de Soja; SM+U- Silagem de Mombaça $+5 \%$ de ureia.

Fonte: Elaboração dos autores.

O teor de digestibilidade in vitro da matéria seca (DIVMS) para silagem de capim-mombaça associada com $5 \%$ ureia foi de $65,14 \%$ aos 15 dias de ensiladas e diferiu $(\mathrm{P}<0,05)$ dos demais tratamentos. A parede celular das células vegetais apresenta estrutura complexa, constituída pelas frações de celulose, hemicelulose e lignina. A associação da lignina com as outras duas frações é responsável pela baixa digestibilidade de muitas forragens (FERNANDES et al., 2009). Neste sentido, o aumento na DIVMS na silagem de capim-mombaça associada com 5\% de ureia foi, provavelmente, resultante do aumento na fração nitrogenada e solubilização parcial da lignina e microfibrilas cristalinas da celulose, que limitam a digestão dos carboidratos estruturais pelos microrganismos do rúmen (LEAL; SHIMADA; HERNÁNDEZ, 1994). Para Jackson (1977), esses resultados de digestibilidade estão relacionados à ocorrência de hidrólise alcalina, pela expansão das moléculas de celulose e pelas rupturas das ligações intermoleculares das pontes de hidrogênio, aumentando a digestão da celulose e hemicelulose. A digestibilidade in vitro é uma técnica que guarda alta correlação com a digestibilidade in vivo Tilley e Terry (1963), notadamente em forrageiras (McLEOD; MINSON, 1969).

A DIVMS é influenciada por vários fatores como a relação lâmina:colmo que decresce com maior idade da forrageira e conseqüentemente elevando os teores de FDN resultando em menor DIVMS (PALIERAQUI et al., 2006). Não houve influencia 
$(\mathrm{P}>0,05)$ (Tabela 9) dos aditivos sobre a DIVMS da silagem de capim-mombaça, o que não está coerente com o comportamento relatados por Balieiro Neto et al., (2007) que foram a redução nos teores de FDN ocasionada pela utilização de aditivo implicando melhor qualidade do volumoso produzido (melhoria na digestibilidade). Por outro lado, Corrêa, Pereira e Oliveira (2003) mencionam que os carboidratos solúveis são considerados a fração de carboidratos mais digestível dos componentes celular. Neste sentido, o consumo de carboidratos solúveis por microrganismos resulta em elevação proporcional da fração fibrosa, reduzindo o valor nutritivo da silagem.

Pereira et al., (2008) ao estudarem diferentes níveis de ureia $(0 ; 0,5 ; 1$ e $1,5 \%)$ em silagem de sorgo, não encontraram diferença significativa para a digestibilidade da matéria seca que foi em média de $64,52 \%$. Isso ocorreu provavelmente, em função dos baixos níveis de ureia testado.

\section{Conclusões}

A adição de farelo de trigo, resíduo de soja e a ureia melhoram as características fermentativas das silagens de capim-mombaça.

A silagem de capim-mombaça associada com 5\% de ureia e sem aditivo apresenta melhores médias para teores de matéria seca aos 45 dias de ensiladas.

A silagem de capim-mombaça associada com $5 \%$ de ureia proporciona maior digestibilidade in vitro da matéria seca aos 15 dias de ensiladas.

\section{Agradecimentos}

Ao CNPq e a Universidade Federal da Grande Dourados pelo apoio financeiro e bolsas concedidas.

\section{Referências}

ALVES, E. M.; PEDREIRA, M. S.; AGUIAR, L. V.; COELHO, C. P.; OLIVEIRA, C. A. S.; SILVA, A. M. P.,
Silagem de sorgo com e sem tanino em substituição à silagem de milho na alimentação de ovinos: desempenho e características de carcaça. Ciência Animal Brasileira, Goiânia, v. 13, n. 2, p. 157-164, 2012.

ÁVILA, C. L. S.; PINTO, J. C.; EVANGELISTA, A. R.; MORAIS, A. R.; FIGUEIREDO, H. C. P.; TAVARES, V. B. Perfil de fermentação das silagens de capim-tanzânia com aditivos -teores de nitrogênio amoniacal e ph. Ciência e Agrotecnologia, Lavras, v. 27, n. 5, p. 11441151, 2003.

AVILA, C. L. S.; PINTO, J. P.; FIGUEIREDO, H. C. P.; MORAIS, A. R.; PEREIRA, O. G.; SCHWAN, R. F., Estabilidade aeróbia de silagens de capim-mombaça tratadas com Lactobacillus buchneri, Revista Brasileira de Zootecnia, Viçosa, v. 38, n. 5, p. 779-787, 2009.

BALIEIRO NETO, G.; SIQUEIRA, G. R.; REIS, R. A.; NOGUEIRA, J. R.; ROTH, M. T. P.; ROTH, A. P. T. P., Óxido de cálcio como aditivo na ensilagem de cana-deaçúcar Revista Brasileira de Zootecnia, Viçosa, v. 36, n. 5, p. 1231-1239, 2007.

BLASER, R. E. Integrated pasture and animal management. Tropical Grasslands, Austrália, v. 16, n. 1, p. 9-24, 1982.

CORREAA, C. E. S.; PEREIRA, M. N.; OLIVEIRA, S. G. Performance of Holstein cows fed sugarcane or corn silages of different grain textures. Scientia Agricola, Piracicaba, v. 60, n. 1, p. 221-229, 2003.

COSTA, N. L.; RODRIGUES, A. N. A.; TOWNSEND, C. R. T.; MAGAlHÃES, J. A.; OLIVEIRA, J. R. C. Calagem e Adubação para Pastagens de Panicum maximum cv. Mombaça em Rondônia. Embrapa: Porto Velho, 2003. 3 p. (Recomendações técnicas, 84).

EMPRESA BRASILEIRA DE PESQUISA AGROPECUÁRIA - EMBRAPA. Sistema brasileiro de classificação de solos. Brasília: Embrapa, 2006. 306 p.

EVANGELISTA, A. R.; ABREU, J. G.; AMARAL, P. N. C.; PEREIRA, R. C.; SALVADOR, F. M.; SANTANA, R. A. V. Produção de silagem de capim-marandu (Brachiaria brizantha stapf cv Marandu) com e sem emurchecimento. Ciência e Agrotecnologia, Lavras, v. 28, n. 2, p. 446-452, 2004.

FERNANDES, F. E. P.; GARCIA, R.; PIRES, A. J. V.; PEREIRA, O. G.; CARVALHO, G. G. P.; OLIVINDO, C. S., Ensilagem de sorgo forrageiro com adição de ureia em dois períodos de armazenamento. Revista Brasileira de Zootecnia, Viçosa, v. 38, n. 11, p. 2111-2115, 2009.

JACKSON, M. G. Review article the alkali treatment os straws. Animal Feed Science and Technology, Amsterdam, v. 2, n. 2, p. 105-130, 1977. 
KLOPFENSTEIN, T. Increasing the nutritive value of crop residues by chemical treatment. In: HUBER, J. T. (Ed.). Upgrading residues and by-products for animals. Boca Raton: CRC Press, 1980. p. 40-60.

LANA, R. P. Nutrição e alimentação animal: mitos e realidades. Viçosa, Editora UFV, 2005. 344 p.

LANES, E. C. M.; OLIVEIRA, J. S.; LOPES, F. C. F.; VILLANI, E. M. A., Silagem de milho como alimento para o período da estiagem: com produzir e garantir boa qualidade. CES Revista, Juiz de Fora, v. 1, n. 1, p. 1-14, 2006.

LEAL, M.; SHIMADA, A.; HERNÁNDEZ, E. The effect of $\mathrm{NH}_{3}$ and/or $\mathrm{SO}_{2}$ on the compositional and histological characteristics of sorghum stover. Animal Feed Science and Technology, Amsterdam, v. 47, n. 1, p. 141-150, 1994.

McLEOD, M. N.; MINSON, D. J. Sources of variation in the in vitro digestibility of tropical grass. Journal of the British Grassland Society, Kenilworth, v. 24, n. 3, p. 244-249, 1969.

MUCK, R. E. Inoculation of silage and its effects on silage quality In: INFORMATIONAL CONFERENCE WITH DAIRY AND FORAGE INDUSTRIES, 1996, Madison. Proceedings. Madison: USDFRC, 1996. p. 43-51.

MUCK, R. E.; KUNG JUNIOR, R. Effects of silage additives on ensiling In: SILAGE: FIELD TO FEEDBUNK, 1., 1997, Pennsylvania. Proceedings... Pennsylvania: NRAES, 1997. p. 187-199.

PALIERAQUI, J. G. B.; FONTES, C. A. A.; RIBEIRO, E. G.; CÓSER, A. C.; MARTINS, C. E.; FERNANDES, A. M. Influência da irrigação sobre a disponibilidade, a composição química, a digestibilidade e o consumo dos capins mombaça e Napier. Revista Brasileira de Zootecnia, Viçosa, v. 35, n. 6, p. 2381-2387, 2006.

PARIZ, C. M.; ANDREOTTY, M.; BERGASMACHINE, A. F.; BUZETTI, S.; COSTA, N. R.; CAVALLINI, M. C.; ULIAN, N. A.; LUIGGI, F. G. Yield, chemical composition and chlorophyll relative content of Tanzania and Mombaça grasses irrigated and fertilized with nitrogen after corn intercropping. Revista Brasileira de Zootecnia, Viçosa, v. 40, n. 4, p. 728-738, 2011.

PEREIRA, O. D.; SOUZA, V. G.; VALADARES FILHO, S. C.; PEREIRA, D. H.; RIBEIRO, K. G. CECON, P. R. Consumo e digestibilidade dos nutrientes e desempenho de bovinos de corte recebendo dietas com diferentes níveis de ureia. Ciência Animal Brasileira, Goiânia, v. 9, n. 3, p. 552-562, 2008.

RODRIGUES, P. H. M.; ALMEIDA, T. F.; MELOTTI, L.; ANDRADE, S. J. T.; PEIXOTO JÚNIOR, K. C.
Efeitos da adição de inoculantes microbianos sobre a composição bromatológica e sobre a fermentação da silagem de girassol produzida em silos experimentais. Revista Brasileira de Zootecnia, Viçosa, v. 30, n. 6, p. 2169-2175, 2001.

RUPPEL, K. A.; PITT, R. E.; CHASE, L. E.; GALTON, D. M., Bunker silo management and its relationship to forage preservation on dairy farms. Journal of Dairy Science, Champaign, v. 78, n. 1, p. 141-153, 1995.

SANTANA, G. S.; BIANCHI, P. P. M.; MORITA, I. M.; ISEPON, O. J.; FERNANDES, F. M. Produção e composição bromatológica da forragem do capimmombaça (Panicum maximum Jacq), submetidos a diferentes fontes e doses de corretivo de acidez. Semina: Ciências Agrárias, Londrina, v. 31, n. 1, p. 241-246, 2010.

SILVA, D. J.; QUEIROZ, A. C. Análise de alimentos: métodos químicos e biológicos. Viçosa, MG: Editora UFV, 2002. $235 \mathrm{p}$.

SILVA, L. F. P.; MACHADO, P. F.; FRANCISCO JUNIOR, J. C.; DONIZETTI, M.; PEREIRA, A. R. Relação entre a composição química e a degradabilidade in situ da matéria seca e da fibra em detergente neutro da fração volumosa de híbridos de milho. Revista Brasileira de Zootecnia, Viçosa, v. 29, n. 1, p. 1-7, 2000.

TAVARES, V. B.; PINTO, J. C.; EVANGELISTA, A. R.; FIGUEIREDO, H. C. P.; ÁVILA, C. L. S.; LIMA, R. F. Efeitos da compactação, da inclusão de aditivo absorvente e do emurchecimento na composição bromatológica de silagens de capim-tanzânia. Revista Brasileira de Zootecnia, Viçosa, v. 38, n. 1, p. 40-49, 2009.

TILLEY, J. M. A.; TERRY, R. A. A two stages technique for the "in vitro" digestion of forage crops. Journal of British Grassland Society, Kenilworth, v. 18, n. 1, p. 104111, 1963.

VAN SOEST, P. J. Nutritional ecology of the ruminant. Cornell University Press New York, 1994. 476 p.

p. 2. ed. Corvallis: O’ B Books, 1987. 373

VAN SOEST, P. J. Symposium on factors influencing the voluntary intake of herbage by ruminants: Voluntary intake relation to chemical composition and digestibility. Journal of Animal Science, New York, v. 24, n. 3, p. 834844, 1965.

VAN SOEST, P. J.; ROBERTSON, J. B.; LEWIS, B. A. Symposium: carbohydrate methodology, metabolism, and nutritional implications in dairy cattle. Journal of Dairy Science, Champaign, v. 74, n. 10, p. 3583-3597, 1991. 
VASCONCELOS, W. A.; SANTOS, E. M.; ZANINE, A. M.; PINTO, T. F.; LIMA, W. C.; EDVAN, R. L.; PEREIRA, O. G. Valor nutritivo de silagens de capimmombaça (Panicum maximum Jacq) colhido em função de idades de rebrotação. Revista Brasileira Saúde Produção Animal, Salvador, v. 10, n. 4, p. 874-884, 2009.

VIEIRA, B. R.; OBEID, J. A.; PEREIRA, O. G.; VALADARES FILHO, S. C.; CARVALHO, I. P. C.; AZEVEDO, J. A. G., Consumo, digestibilidade dos nutrientes e parâmetros ruminais em bovinos alimentados com silagem de capim-mombaça. Arquivo Brasileiro de Medicina Veterinária e Zootecnia, Belo Horizonte, v. 62, n. 5, p. 1148-1157, 2010.
WILSON J. R. Cell wall characteristics in relation to forage digestion by ruminants. Journal of Agriculture Science, Toronto, v. 122, n. 1, p. 173-182, 1994.

WOOLFORD, M. K. The silage fermentation. New York: Marcel Dekker, 1984. 350 p.

ZAGO, C. P. Silagem de milho e sorgo. Consultor das Sementes Biomatrix. Patos de Minas: [s.n], 2011. Disponível em: <http://wwwbiomatrixcombr/resources/ download php?file=/pdf $>$. Acessado em: 17 dez. 2011.

ZANINE, A. M.; SANTOS, E. D.; FERREIRA, D. J.; OLIVEIRA, J. S.; PEREIRA, O. G. Avaliação da silagem de capim-elefante com adição de farelo de trigo. Archivos de Zootecnia, Córdoba, v. 55, n. 209, p. 75-84, 2006. 
